\title{
Literature-Based Appraisal of Racial/Ethnic Cardiovascular Health Care Disparities
}

\author{
Samuel T. Savitz \\ The Lewin Group, 3130 Fairview Park Drive, Suite 500, Falls Church, VA 22042, USA \\ Correspondence should be addressed to Samuel T. Savitz, sam.savitz@lewin.com
}

Received 9 October 2011; Accepted 15 November 2011

Academic Editors: A. Bramesfeld and H. B. Bueno-de-Mesquita

Copyright () 2012 Samuel T. Savitz. This is an open access article distributed under the Creative Commons Attribution License, which permits unrestricted use, distribution, and reproduction in any medium, provided the original work is properly cited.

While racial and ethnic disparities in cardiovascular disease care have been recognized for some time, this growing literature has not integrated heterogeneities within populations and sufficient research on certain populations. This paper consists of a literature review of disparities for cardiovascular disease care in the United States using the Academic SearchComplete, a function of EBSCOhost. The purpose of the review is to evaluate the current state of the literature and determine the implications for eliminating these disparities. The search revealed an extensive literature on cardiovascular health disparities, although, the identified articles neglected certain population groups and certain sub-populations within well-researched groups. The causal pathways documented in the literature suggest that improvements are feasible in the near future, but the elimination of them would require concerted effort over a longer period.

\section{Introduction}

Pronounced extensive disparities exist for cardiovascular (CV) disease in the United States. Considering racial and ethnic disparities alone, we know that Blacks between the ages of 20 and 64 are more than twice as likely to die from cardiovascular disease as Whites [1]. Furthermore, the percentage of premature deaths due to heart disease is higher among Blacks (31.5\%), American Indians (36\%), Asians and Pacific Islanders (21.1\%), and Hispanics (23.5\%) than among Whites (14.7\%) [2]. A multitude of possible explanations exist for health disparities such as these, including racial income inequalities and provider discrimination [3-5].

This paper focuses on the factors leading to racial/ethnic disparities in health care for cardiovascular disease. Disparities in health care refer to unequal treatment of patient subgroups with similar medical conditions, needs, and preferences [6]. This may include frequency of blood-pressure testing, prescribing medications for elevated cholesterol, availability of preventive screening tests, or providing Coronary Artery Bypass Graft surgery. The paper explores such disparities by dividing the issue into the following sections: (i) description of CV health care disparities; (ii) explanations of causal pathways that lead to these disparities; (iii) evaluation of how comprehensively the literature has examined this disparity; (iv) discussion on efforts to further understand this disparity; (v) evaluation of efforts to reduce this disparity.

\section{Methods}

To conduct the literature search, the Academic Search Complete tool was utilized to search for articles from 1995 to the present. This tool is a function of EBSCOhost, which is an online database of more than 12,500 journals. The search terms included "cardiovascular," "healthcare," "health," and "disparities" and yielded 183 articles. An article was considered relevant if it pertained to racial/ethnic disparities in cardiovascular health care. Articles were eliminated if they covered health conditions other than cardiovascular disease or types of disparities other than race and ethnicity (e.g., urban/rural or socioeconomic) and those pertaining to populations outside the United States. The relevancy of the articles was determined by first looking at the titles, then reviewing the abstracts, and finally reading the full article. Additional articles were found reviewing the works cited in 
the identified articles. Based on this review, 55 papers meeting the inclusion criteria were fully reviewed and are incorporated into the following discussion.

\section{Discussion}

3.1. Description of the Disparities. A systematic search of the peer-reviewed literature reveals that racial/ethnic health care disparities exist for a wide range of CV services and that these disparities are often substantial in magnitude. The most consistent findings were for Blacks and Hispanics relative to nonHispanic Whites, though some studies showed disparities between Asians or Native American and Whites. Since disparities for surgery and preventive care are very different in terms of costs, patient-provider interaction, and access to health care, they are discussed separately.

3.1.1. Surgical Care. There are differences in care favoring Whites over Blacks for nearly every type of cardiac care $[7,8]$. In their review of the literature, Kressin and Petersen [9] found that the odds ratios for Blacks versus Whites across the country were between 0.41 and 0.94 for cardiac catheterization, and for percutaneous transluminal coronary angioplasty between 0.32 and 0.8 , meaning that Blacks were less likely than Whites to receive the treatment controlling for health status. For coronary artery bypass graft (CABG) surgery, the odds ratios were between 0.22 and 0.68 for Blacks, again significantly less than for Whites [9], corroborated in another review [10] and in a study within the VA system [11]. While not all of these odds ratios were statistically significant, not one of them had an odds ratio of one or greater, providing consistent evidence that Blacks receive these surgeries at lower rates than do Whites. The largest disparity was for Left Ventricular Assist Device Therapy, which is an expensive treatment for patients with congestive heart failure. The odds ratio for this treatment is 0.29 for Blacks relative to Whites [12].

Even when minorities receive treatment, there are differences in the quality of care. For instance, there are disparities in the door-to-balloon time, which measures how long until a heart attack patient receives a balloon angioplasty after arrival at the emergency department. Blacks and Hispanics had significantly longer wait times than Whites even after controlling for potential confounders [13]. Such differences in care help to explain disparities in outcomes for Blacks after inpatient CV care. Blacks have a higher-risk adjusted rate of mortality after acute myocardial infarction (AMI) [14] and are $25 \%$ more likely to be readmitted within 30 days (versus Whites) when receiving care at hospitals that primarily serve nonminorities [15]. The evidence is more limited and mixed for Hispanics, Asians, and American Indians [9, 16]. Only one identified study included American Indians and Alaskan Natives (AIAN) and the findings showed similar care for AIAN compared to Whites in California hospitals. However, this paper was a response to findings of significant disparities in other parts of the country between AIAN and Whites [16]. Without more evidence, conclusions cannot be drawn regarding disparities for groups other than Blacks.
3.1.2. Preventive Care. Similar racial disparities are found for both primary and secondary preventive CV care. A study in the US Medicare populations showed that Blacks were significantly less likely to receive blood pressure control (OR 0.87) and beta-blockers after MI (OR 0.64), and both Blacks and Hispanics were significantly less likely to receive cholesterol management after an acute CV event (OR 0.64 and 0.72, resp.) [17]. A separate study found that, in the general population, Blacks were significantly less likely to receive betablockers after an MI [18]. Additionally, Blacks (35.4\%) and Hispanics $(30.3 \%)$ were significantly less likely to receive cholesterol screening than Whites (46.4\%) [19]. However, this relationship may be diminished in the Veteran Affairs system due to equal access that are enjoyed by veterans. A study of US Southwest Veterans found no significant differences in blood pressure and lipid control [20]. However, another study covering the whole VA system showed that Blacks were significantly less likely to be prescribed betablockers (OR 0.74) or statins (OR 0.54) [11]. Thus, significant disparities still exist for preventive CV care within the VA.

3.2. Causal Pathways. A variety of factors are likely to contribute to these disparities in CV care, considered below.

3.2.1. Confounding Race with Other Variables. Blacks and Hispanics are more likely to come from a low SES background, [21] receive care at lower-quality hospitals [22], and qualify for Medicaid [23]. This explanation minimizes the role that race has by suggesting that race and these other variables are confounded by SES and its correlates. One researcher suggests that if more studies looked at how treatment differed within the same institution, many of these disparities would no longer exist [24]. Blacks and Hispanics are much more likely to get their care at hospitals that perform a low-volume of CV care, and these hospitals have significantly worse outcomes for their CV patients [22]. Also, financial barriers are much more likely for Blacks and Hispanics, and those that face these barriers are significantly more likely to have cardiac rehospitalization (OR 1.7) [25]. Thus, these differences play a role in the poorer health services received by Blacks and Hispanics. However, they do not explain the entirety of these disparities. After controlling for these factors or when the data came from the same system (e.g., Medicare or the VA), the disparities were partly but not completely accounted for $[7,11,13,15,23,26]$.

3.2.2. Provider Bias and Attitudes. Unconscious bias towards minorities is a widely documented problem within the medical profession [6]. A study observing interactions between physicians and patients noted that physicians were $23 \%$ more likely to be verbally dominant and performed 33\% less patient-centered communication with Black than with White patients [8]. In regard to CV care, race is a significant predictor for recommendations of angiograms among male patients [27]. Also, a study conducted a survey with actors portraying patients that had an equal distribution of health conditions. The results showed that physicians were less likely to 
refer Blacks for cardiac catheterization and especially unlikely to refer Black women [28].

Despite strong evidence for these health disparities and bias among providers, physicians are largely in denial about these health disparities. Only 33\% of cardiologists acknowledged that disparities of care exist within cardiology, while only $5 \%$ admitted that disparities exist for the patients that they treat [29]. This denial is part of the reason why these disparities continue; with so few physicians realizing they have these biases, they do not know that they should be taking steps to remedy them. Research shows that, to counteract these biases, physicians must consciously recognize them and work to address the problem [27]. Other explanations for why these biases occur and lead to differential outcomes is clinical uncertainty [6] and the high levels of stress that physicians face due to time constraints and pressure to perform [30]. Finding ways to mitigate these disparities will require engaging physicians to eliminate or reduce these biases.

3.2.3. Limitation of Specialty Care. Blacks are much less likely to see a cardiologist compared to Whites [31]. One reason for this is that Blacks are less likely to have a usual source of care, which affects physician referral in obtaining specialized cardiology services [6]. Additionally, primary care physicians claim they have more difficulty identifying specialists willing to accept referrals for minority patients who are often (un) underinsured $[6,32]$. Further, there is double jeopardy in many cases because minority physicians are more likely to treat minority patients, and these physicians are less able to secure specialists for their patients [6]. Thus, Blacks and other minorities face difficulties in securing access to cardiologists.

In addition, Blacks are less likely to be transferred from hospitals that are poorly equipped to handle CV care [33]. Thus, Blacks are more likely to get inadequate care even if they get initial treatment at the same hospital as Whites. Lastly, new therapies tend to be integrated into the care for communities of color at slower rates than for Whites [34], for example, heart stents [35]. Together, this evidence suggests that minorities face more difficulty securing care at the hospital level in addition to the provider level.

3.2.4. Patient-Level Characteristics. Minorities are more likely to lack health literacy because of language barriers, cultural barriers, and limited educational opportunities. Limited health literacy is significantly associated with being Black compared to being White (OR 7.81) [36]. A study conducting focus groups found that Blacks and Whites had similar general knowledge about the risk factors for CV disease, but that Blacks had less specific knowledge about them [37]. While no research was reported in the peer-reviewed literature on whether these differences in health literacy lead to poor health outcomes, this is posited to be a plausible causal pathway. Blacks are more likely to delay seeking care for acute coronary syndrome and would be more likely to seek care earlier if they had more familiarity with the signs of this condition [38]. Further, the study using focus groups found Blacks to be less assertive with their providers than Whites [37]. More knowledge about their condition could make Black patients more comfortable being assertive with their physicians. Additionally, instruction on asking questions may also improve the communication between physicians and minority patients. For example, the provision of a sheet suggesting questions to ask about cardiovascular health could facilitate discussion. When this tactic was used in Australian hospitals for advanced cancer patients, there were significant increases in the number of questions asked and issues discussed [39]. Such prompting would help all patients, but especially Blacks because they tend to have less specific knowledge relating to $\mathrm{CV}$ and more to gain by asking questions.

Language is also an important factor. Hispanics who are proficient in English were more likely to receive advice about physical exercise (OR 1.5), diet (OR 1.5), or both (OR 1.6) [40]. It is important to note that this causal pathway is not independent of provider bias: the reason why minorities have lower health literacy is related to the relationships they have had with their physicians. This way of looking at the problem suggests that interventions should target improving health literacy among patients.

3.3. Gaps in the Literature. The studies that were identified covered a broad range of CV services and potential explanations for why racial/ethnic disparity exists. Specifically, the literature adequately covered disparities for $\mathrm{CV}$ treatment for Blacks and to a lesser extent Hispanics and causal pathways. However, the literature did not go into sufficient depth on other population besides Blacks and Hispanics and differences within populations.

The first major deficiency of the literature was too little attention on CV health care disparities that may exist for non-Blacks. All studies except one reported findings on Blacks, whereas there was data on Hispanics in about half of the studies, and only a few that reported results for Asians and American Indians and Alaskan Natives (AIAN). With so few studies on Asians and AIAN, it is difficult to make strong conclusions about whether there are disparities for these groups. The advantage of having a large literature to draw from is that studies can be checked against others to determine whether there is a consensus about reported relationships and reliability of measurable, observed differences. There are sufficient studies to do this for the Black population and to a lesser extent the Hispanic population. Thus, more research is necessary on other vulnerable populations. Research on different populations will also improve understanding of how patterns and causal pathways operate for Blacks and Hispanics.

The second gap in the reviewed literature was that it largely did not account for heterogeneities within populations. Two notable omissions were acculturation/language proficiency and skin color. Level of acculturation is a potentially important social determinant of health that could influence CV health care, among other areas of health. The study mentioned earlier, which found that Hispanics who had limited English speaking skills received physician advice about dieting and exercise at lower rates, suggested that this 
result may be due in part to acculturation. This implies that English speaking abilities would be a proxy for acculturation [40]. However, this was the sole study to mention the role that acculturation may play. The studies on Asian Americans did not mention how the experience that Asian immigrants face may differ from the rest of the Asian population together with the heterogeneity of this group. There may be a hidden disparity in this case as Asian immigrants with less acculturation or more limited English speaking skills may not receive the same level of care that native-born Asian Americans receive [41]. Additionally, acculturation was not mentioned in any of the studies on Blacks. While Black immigration has not been very large historically, there has been increasing numbers of Black immigrants from West Africa, Latin America, and the Caribbean. In 2005, the foreign-born Black population number was about 2.8 million, which is about $8 \%$ of the US Black population [42]. It would be easy for researchers to also track immigration source (i.e., home country of origin) as one of the variables they examine and is important given the sizable proportion of Black immigrants.

Acculturation may be important because it relates to both provider bias and health literacy. Physicians may carry biases against immigrants on top of the biases they have against certain racial or ethnic groups. For example, physicians may assume that someone who is not very acculturated will not understand instructions. Additionally, physicians may be unwilling to respect cultural practices relating to medicine. Further, people who are not very acculturated may have limited health literacy or feel less comfortable. Thus, level of acculturation could plausibly impact this disparity and there should be additional research to understand its influence.

Also, researchers ignore the impact that skin color has as a social determinant of health. None of the studies in my review examined this variable. In most Western societies, darker skin color is associated with lower socioeconomic status [43]. In relation to health, some studies suggest that darker skin color is correlated with higher blood pressure among Blacks [44]. Similarly, Hispanics with darker skin have lower pay [45] and higher rates of hypertension [44]. While these results may point to genetic differences, it is much more likely that they point to how skin color acts as a social determinant through increased discrimination; that is, someone is more likely to discriminate or act in a more discriminatory manner against a Black or Hispanic with darker skin.

In the area of health care, darker skin color may increase provider bias and stereotyping. The above evidence suggests that discrimination increases against Blacks and Hispanics with darker skin among society in general and possibly for physicians. If true, policymakers may want to design cultural competency programs to incorporate skin color if the preponderance of discrimination is against these groups. Also, researchers could stratify racial groups by subcategories based on skin color. There are some cases when the differences between minority groups and Whites were not apparent and they may have been influential for the subgroup of that minority with darker skin.

3.4. Improving Research on This Disparity. Measuring acculturation requires some creativity to measure. One important characteristic is how long someone has been in the US. The longer someone is in the US, the more time they have had to assimilate into American culture [46]. Also, English-speaking ability is critical for communication and was associated with fewer Hispanic patients receiving advice [40]. Further, having family members in the US already helps people to assimilate faster. Lastly, the age at which someone immigrates into the US is relevant, since children can assimilate more quickly than adults [46]. Additionally, there could also be a self-assessment of the degree of acculturation. Researchers can then examine these variables individually for their predictive value and also as a composite score.

Skin color is an easier characteristic to measure, though it is challenging to understand how it affects discrimination. Researchers simply need to determine someone's skin pigmentation and place it along a continuum. However, research is necessary to determine whether discrimination occurs more intensely or frequently depending on one's skin color in the health care arena, though there is research documenting different levels of wage discrimination depending on darkness and lightness of one's skin color [47].

This is difficult because there may be increased discrimination in all areas of life and it would be hard to specifically attribute the specific impact that discrimination within the health care system has separately from the ways in which discrimination limits educational opportunities, lowers income, and so forth, which in turn affects the quality of health care. This is also a problem for acculturation, since immigrants face discrimination in other areas besides that in healthcare [48]. To isolate the effect of skin color or acculturation, researchers should control for potential confounders in their analysis.

Studies could focus on physician behavior instead of patient outcomes. Physician behavior should not be affected by what these patients experience outside of a hospital setting. Specifically, they could measure the rate at which physicians offer preventive tests and services. The physician directly controls the ability to offer such service, and, thus, differences should indicate provider bias. To measure the provision of such care, researchers could either ask patients or fund medical testers. These testers should have an even distribution of characteristics so that the differences in health care quality could be attributed to skin color or acculturation [49]. However, it is worth noting that medical testing is a difficult method for research because of the high cost.

3.5. Evaluation of Efforts to Reduce This Disparity. While the literature demonstrates how extensive a problem CV health care disparities is, there have been successful interventions that have led to convergences between the care received by minorities and Whites. Thus, it is feasible to considerably reduce these disparities by 2020 .

Past interventions show that providers respond well to feedback about their quality of care [50]. Increased tracking and feedback on quality would provide physicians incentives to counter their stereotypes and biases. They could also encourage hospital administration to make access to resources and specialists easier for minorities. A literature 
review of interventions to reduce health care disparities found that external accountability in the form of reporting was often a major component of successful initiatives [51]. Facilities participating in the American Heart Association's Get With The Guidelines Program achieve 90\% or greater adherence to the core measures for coronary artery disease and heart failure for all racial/ethnic groups [52]. Likewise, an initiative within Medicare managed care plans to measure provision of care decreased a divergence of 11 points for postmyocardial infarction beta-blockers between White and Black patients (76\% versus 64$)$ to one point (94\% versus 93\%) over five years [53]. Thus, feedback and recording of data seem to encourage physicians to meet guidelines and provide high-quality care for all patients.

Additional interventions focus on encouraging physicians to provide more culturally appropriate care to minority patients. Such programs could give providers the tools to address bias and stereotyping against minorities. Some interven tions that have addressed provision of culturally appropriate care have led to significant improvements in quality [54]. For instance, one intervention had culturally specific community health workers and nurse practitioners working with physicians, which led to a decrease in blood pressure and left ventricular hypertrophy in Black men [55]. Also, another study found that cultural competency training leads to improved provider attitudes, knowledge, and patient satisfaction [56]. Thus, addressing the way providers work with minority patients has the potential for reducing these disparities.

Considering the success of these two types of interventions, significant reduction in these disparities in CV care by 2020 is feasible. These programs would need to be applied to health care facilities nationwide. Also, the facilities and the physicians within them would need to prioritize these programs and address their role in contributing to these disparities in care. Further, there would need to be government support in the form of funding and tracking of CV care. Cultural competency training would likely be too expensive for health care facilities to be willing to pay for by themselves. There is already funding support for cultural competency training in the Patient Protection and Affordability Act [57]. Also, tracking would need to be uniform nationwide to produce the data that is comparable. It is possible that a large reduction in the disparities for CV care will occur, but only if actions are put in place to provide support.

\section{Summary and Conclusions}

The reported literature search documents extensive racial disparities in CV health care. Causal pathways identified were differences in hospitals where minorities seek care, physician bias against minorities in regimens of care, bias against minorities in access to resources, and limited health literacy and assertiveness among minorities. Next, omissions in the literature were discussed: research on non-Black minorities, the impact of acculturation, and the role of skin pigmentation. The paper further explained how researchers could begin measuring the latter two deficiencies to develop a greater understanding of the social determinants of this disparity. Finally, several interventions to address healthcare disparities were detailed. The conclusion is that a concerted effort to address this disparity with similar interventions could lead to significant convergence in these disparities by 2020 .

Given this potential, disparities in CV care should be a focus for Healthy People 2020 and future incarnations of Healthy People. Healthy People 2020 includes health disparities as one of the four foundation health measures [58]. Specifically, the plan is to track disparities along racial and ethnic lines, among other categories. The goal with regard to health disparities is "to achieve health equity, eliminate disparities, and improve the health of all groups" [59]. While this goal is commendable, it is clear that health disparities will not be entirely eliminated by 2020. Resources will have to be prioritized towards the most important issues and collection of necessary data to achieve these gaps. The research shows extensive disparities in cardiovascular care and ways to address them. Further, heart disease accounts for a high proportion of premature deaths among Blacks (31.5\%), American Indians (36\%), Asians and Pacific Islanders (21.1\%), and Hispanics (23.5\%) [2]. While many of the societal inequities that underlie health disparities are extremely difficult to modify, this is one that has been shown to be amenable to effective intervention. Thus, disparities in CV care should be a priority highlighted for achieving this Healthy People 2020 goal.

\section{Acknowledgments}

The author would like to express appreciation for reviews from Sherman James, Ph.D., Lucy Savitz, Ph.D., and David Savitz, Ph.D. The author wrote this paper while attending Duke University, and before being affiliated at with the Lewin Group.

\section{References}

[1] National Center for Health Statistics, Worktable 210R: death rates for 113 selected causes, alcohol-induced causes, drug-induced causes, and injury by firearms, by five-year age groups, race, and sex, Centers for Disease Control and Prevention, Atlanta, Ga, USA, 2002.

[2] Centers for Disease Control and Prevention, Disparities in premature deaths from heart disease-50 states and the District of Columbia 2001, Centers for Disease Control and Prevention, Atlanta, Ga, USA, 2010.

[3] L. Braun, "Race, ethnicity, and health: can genetics explain disparities?" Perspectives in Biology and Medicine, vol. 45, no. 2, pp. 159-174, 2002.

[4] W. W. Dressler, K. S. Oths, and C. C. Gravlee, "Race and ethnicity in public health research: models to explain health disparities," Annual Review of Anthropology, vol. 34, pp. 231-252, 2005.

[5] A. T. Geronimus, M. Hicken, D. Keene, and J. Bound, "'Weathering" and age patterns of allostatic load scores among blacks and whites in the United States," American Journal of Public Health, vol. 96, no. 5, pp. 826-833, 2006.

[6] B. D. Smedley, A. Y. Stith, and A. R. Nelson, Unequal treatment: confronting racial and ethnic disparities in health care, Institute of Medicine, Washington, DC, USA, 2003. 
[7] J. J. Allison, C. I. Kiefe, R. M. Centor, J. B. Box, and R. M. Farmer, "Racial differences in the medical treatment of elderly medicare patients with acute myocardial infarction," Journal of General Internal Medicine, vol. 11, no. 12, pp. 736-743, 1996.

[8] R. L. Johnson, D. Roter, N. R. Powe, and L. A. Cooper, "Patient race/ethnicity and quality of patient-physician communication during medical visits," American Journal of Public Health, vol. 94, no. 12, pp. 2084-2090, 2004.

[9] N. R. Kressin and L. A. Petersen, "Racial differences in the use of invasive cardiovascular procedures: review of the literature and prescription for future research," Annals of Internal Medicine, vol. 135, no. 5, pp. 352-366, 2001.

[10] M. Lillie-Blanton, T. M. Maddox, O. Rushing, and G. A. Mensah, "Disparities in cardiac care: rising to the challenge of Healthy People 2010," Journal of the American College of Cardiology, vol. 44, no. 3, pp. 503-508, 2004.

[11] J. L. Mehta, Z. Bursac, P. Mehta et al., "Racial disparities in prescriptions for cardioprotective drugs and cardiac outcomes in veterans affairs hospitals," American Journal of Cardiology, vol. 105, no. 7, pp. 1019-1023, 2010.

[12] D. L. Joyce, J. V. Conte, S. D. Russell, L. D. Joyce, and D. C. Chang, "Disparities in access to left ventricular assist device therapy," Journal of Surgical Research, vol. 152, no. 1, pp. 111117, 2009.

[13] E. H. Bradley, J. Herrin, Y. Wang et al., "Racial and ethnic differences in time to acute reperfusion therapy for patients hospitalized with myocardial infarction," Journal of the American Medical Association, vol. 292, no. 13, pp. 1563-1572, 2004.

[14] J. Skinner, A. Chandra, D. Staiger, J. Lee, and M. McClellan, "Mortality after acute myocardial infarction in hospitals that disproportionately treat black patients," Circulation, vol. 112, no. 17, pp. 2634-2641, 2005.

[15] K. E. Joynt, E. J. Orav, and A. K. Jha, “Thirty-day readmission rates for medicare beneficiaries by race and site of care," Journal of the American Medical Association, vol. 305, no. 7, pp. 675-681, 2011.

[16] S. Jolly, C. Kao, A. B. Bindman, and C. Korenbrot, "Cardiac procedures among American Indians and Alaska natives compared to non-hispanic whites hospitalized with ischemic heart disease in California," Journal of General Internal Medicine, vol. 25, no. 5, pp. 430-434, 2010.

[17] B. A. Virnig, N. Lurie, Z. Huang, D. Musgrave, A. Marshall McBean, and B. Dowd, "Racial variation in quality of care among medicare+choice enrollees," Health Affairs, vol. 21, no. 6, pp. 224-230, 2002.

[18] E. C. Schneider, A. M. Zaslavsky, and A. M. Epstein, "Racial disparities in the quality of care for enrollees in medicare managed care," Journal of the American Medical Association, vol. 287, no. 10, pp. 1288-1294, 2002.

[19] M. N. Willson, J. J. Neumiller, D. A. Sclar, L. M. Robison, and T. L. Skaer, "Ethnicity/Race, use of pharmacotherapy, scope of physician-ordered cholesterol screening, and provision of diet/nutrition or exercise counseling during us office-based visits by patients with hyperlipidemia," American Journal of Cardiovascular Drugs, vol. 10, no. 2, pp. 105-108, 2010.

[20] C. S. Wendel, J. H. Shah, W. C. Duckworth, R. M. Hoffman, M. J. Mohler, and G. H. Murata, "Racial and ethnic disparities in the control of cardiovascular disease risk factors in Southwest American veterans with type 2 diabetes: the Diabetes Outcomes in Veterans Study," BMC Health Services Research, vol. 6, article no. 58, 2006.
[21] R. N. Rooks, E. M. Simonsick, L. M. Klesges, A. B. Newman, H. N. Ayonayon, and T. B. Harris, "Racial disparities in health care access and cardiovascular disease indicators in black and white older adults in the health ABC study," Journal of Aging and Health, vol. 20, no. 6, pp. 599-614, 2008.

[22] A. N. Trivedi, T. D. Sequist, and J. Z. Ayanian, "Impact of hospital volume on racial disparities in cardiovascular procedure mortality," Journal of the American College of Cardiology, vol. 47, no. 2, pp. 417-424, 2006.

[23] D. M. Carlisle, B. D. Leake, and M. F. Shapiro, "Racial and ethnic disparities in the use of cardiovascular procedures: associations with type of health insurance," American Journal of Public Health, vol. 87, no. 2, pp. 263-267, 1997.

[24] R. B. Yates and B. C. Hiestand, "Effects of age, race, and sex on door-to-electrocardiogram time in emergency department non-ST elevation acute coronary syndrome patients," Journal of Emergency Medicine, vol. 40, no. 2, pp. 123-127, 2011.

[25] A. R. Rahimi, J. A. Spertus, K. J. Reid, S. M. Bernheim, and H. M. Krumholz, "Financial barriers to health care and outcomes after acute myocardial infarction," Journal of the American Medical Association, vol. 297, no. 10, pp. 1063-1072, 2007.

[26] G. L. Daumit, J. A. Hermann, J. Coresh, and N. R. Powe, "Use of cardiovascular procedures among black persons and white persons: a 7-year nationwide study in patients with renal disease," Annals of Internal Medicine, vol. 130, no. 3, pp. 173182, 1999.

[27] M. Van Ryn, D. Burgess, J. Malat, and J. Griffin, "Physicians' perceptions of patients' social and behavioral characteristics and race disparities in treatment recommendations for men with coronary artery disease," American Journal of Public Health, vol. 96, no. 2, pp. 351-357, 2006.

[28] K. A. Schulman, J. A. Berlin, W. Harless et al., "The effect of race and sex on physicians' recommendations for cardiac catheterization," New England Journal of Medicine, vol. 340, no. 8, pp. 618-626, 1999.

[29] N. Lurie, A. Fremont, A. K. Jain et al., "Racial and ethnic disparities in care: the perspectives of cardiologists," Circulation, vol. 111, no. 10, pp. 1264-1269, 2005.

[30] S. T. Fiske, "On prejudice \& the brain," Daedalus, vol. 136, no. 1, pp. 156-159, 2007.

[31] J. Z. Ayanian, M. B. Landrum, E. Guadagnoli, and P. Gaccione, "Specialty of ambulatory care physicians and mortality among elderly patients after myocardial infarction," New England Journal of Medicine, vol. 347, no. 21, pp. 1678-1686, 2002.

[32] P. B. Bach, H. H. Pham, D. Schrag, R. C. Tate, and J. L. Hargraves, "Primary care physicians who treat blacks and whites," New England Journal of Medicine, vol. 351, no. 6, pp. 575-584, 2004.

[33] J. Suls and R. Martin, "Heart disease occurs in a biological, psychological, and social matrix: cardiac risk factors, symptom presentation, and recovery as illustrative examples," Annals of Behavioral Medicine, vol. 41, no. 2, pp. 164-173, 2011.

[34] A. F. Sonel, C. B. Good, J. Mulgund et al., "Racial variations in treatment and outcomes of black and white patients with high-risk non-ST-elevation acute coronary syndromes: insights from CRUSADE (can rapid risk stratification of unstable angina patients suppress adverse outcomes with early implementation of the ACC/AHA guidelines?)," Circulation, vol. 111, no. 10, pp. 1225-1232, 2005.

[35] Centers for Disease Control and Prevention, National hospital discharge survey, QuickStats: use of stents among hospitalized patients undergoing coronary angioplasty, by race-United States, 2003, The Centers for Disease Control and Prevention, Atlanta, Ga, USA, 2003. 
[36] R. M. Parker, S. C. Ratzan, and N. Lurie, "Health literacy: a policy challenge for advancing high-quality health care," Health Affairs, vol. 22, no. 4, pp. 147-153, 2003.

[37] L. D. Woodard, M. T. Hernandez, E. Lees, and L. A. Petersen, "Racial differences in attitudes regarding cardiovascular disease prevention and treatment: a qualitative study," Patient Education and Counseling, vol. 57, no. 2, pp. 225-231, 2005.

[38] D. K. Moser, L. P. Kimble, M. J. Alberts et al., "Reducing delay in seeking treatment by patients with acute coronary syndrome and stroke: a scientific statement from the American Heart Association Council on Cardiovascular Nursing and Stroke Council," Circulation, vol. 114, no. 2, pp. 168-182, 2006.

[39] J. M. Clayton, P. N. Butow, M. H. N. Tattersall et al., "Randomized controlled trial of a prompt list to help advanced cancer patients and their caregivers to ask questions about prognosis and end-of-life care," Journal of Clinical Oncology, vol. 25, no. 6, pp. 715-723, 2007.

[40] C. Lopez-Quintero, E. M. Berry, and Y. Neumark, "Limited english proficiency is a barrier to receipt of advice about physical activity and diet among Hispanics with chronic diseases in the United States," Journal of the American Dietetic Association, vol. 109, no. 10, pp. 1769-1774, 2009.

[41] S. P. Tanjasiri, S. P. Wallace, and K. Shibata, "Picture imperfect: hidden problems among Asian Pacific Islander elderly," Gerontologist, vol. 35, no. 6, pp. 753-760, 1995.

[42] M. M. Kent, Immigration and America's black population, Population Reference Bureau, Washington, DC, USA, 2007.

[43] J. L. Hochschild and V. Weaver, "The skin color paradox and the American racial order," Social Forces, vol. 86, no. 2, pp. 643-670, 2007.

[44] L. N. Borrell, "Race, ethnicity, and self-reported hypertension: analysis of data from the national health interview survey, 1997-2005," American Journal of Public Health, vol. 99, no. 2, pp. 313-319, 2009.

[45] J. Hersch, "Skin color, immigrant, wages, and discrimination," in Racism in the 21st Century, R. E. Hall, Ed., Springer, Berlin, Germany, 2008.

[46] A. A. Siatkowski, "Hispanic acculturation: a concept analysis," Journal of Transcultural Nursing, vol. 18, no. 4, pp. 316-323, 2007.

[47] A. H. Goldsmith, D. Hamilton, and W. Darity, "From dark to light: skin color and wages among African-Americans," Journal of Human Resources, vol. 42, no. 4, pp. 701-738, 2007.

[48] K. Liebkind and I. Jasinskaja-Lahti, "The influence of experiences of discrimination on psychological stress: a comparison of seven immigrant groups," Journal of Community and Applied Social Psychology, vol. 10, no. 1, pp. 1-16, 2000.

[49] S. Dorn, M. A. Dowell, and J. Perkins, "Anti-discrimination provisions and health care access: new slants on old approaches," Clearinghouse Review, vol. 20, p. 439, 1986.

[50] E. Peterson and C. W. Yancy, "Eliminating racial and ethnic disparities in cardiac care," New England Journal of Medicine, vol. 360, no. 12, pp. 1172-1174, 2009.

[51] R. G. Jones, A. N. Trivedi, and J. Z. Ayanian, "Factors influencing the effectiveness of interventions to reduce racial and ethnic disparities in health care," Social Science and Medicine, vol. 70, no. 3, pp. 337-341, 2010.

[52] Robert Wood Johnson Foundation, Expecting success: excellence in cardiac care results from Robert Wood Johnson Foundation Quality Improvement Collaborative, Robert Wood Johnson Foundation, Princeton, NJ, USA, 2008.
[53] A. N. Trivedi, A. M. Zaslavsky, E. C. Schneider, and J. Z. Ayanian, "Trends in the quality of care and racial disparities in medicare managed care," New England Journal of Medicine, vol. 353, no. 7, pp. 692-700, 2005.

[54] T. L. Fisher, D. L. Burnet, E. S. Huang, M. H. Chin, and K. A. Cagney, "Cultural leverage: interventions using culture to narrow racial disparities in health care," Medical Care Research and Review, vol. 64, no. 5, pp. 243S-282S, 2007.

[55] M. N. Hill, H. R. Han, C. R. Dennison et al., "Hypertension care and control in underserved urban African American men: behavioral and physiologic outcomes at 36 months," American Journal of Hypertension, vol. 16, no. 11 I, pp. 906-913, 2003.

[56] M. C. Beach, L. A. Cooper, K. A. Robinson et al., "Strategies for improving minority healthcare quality," Evidence Report/Technology Assessment (Summary), no. 90, pp. 1-8, 2004.

[57] D. P. Andrulis, N. J. Siddiqui, J. P. Purtle, and L. Duchon, Patient Protection and Affordable Care Act of 2010: Advancing Health Equity for Racially and Ethnically Diverse Populations, Joint Center for Political and Economic Studies, Washington, DC, USA, 2010.

[58] "Healthy People 2020. Foundation Health Measures," Washington, DC: U.S. Department of Health and Human Services, 2011, http://www.healthypeople.gov/2020/about/tracking .aspx.

[59] "Healthy People 2020. Disparities," Washington, DC: U.S. Department of Health and Human Services, 2011, http://www .healthypeople.gov/2020/about/DisparitiesAbout.aspx. 


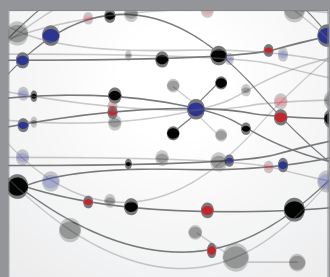

The Scientific World Journal
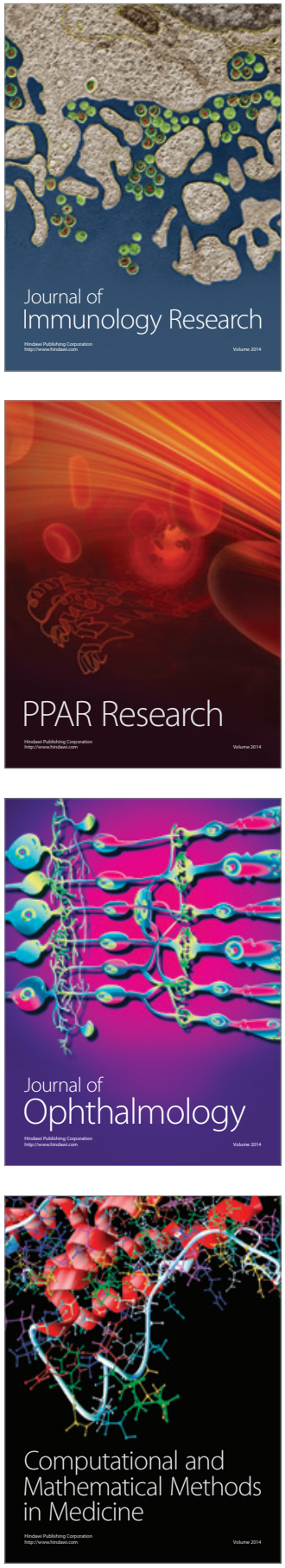

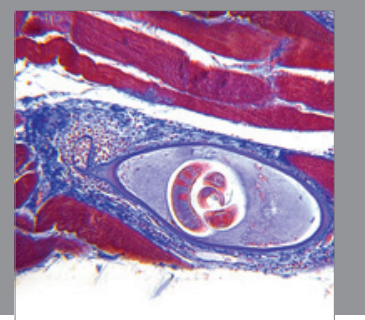

Gastroenterology

Research and Practice
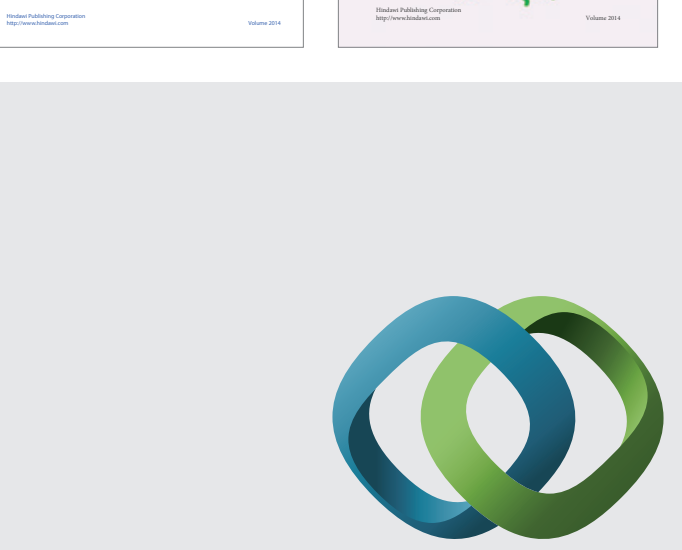

\section{Hindawi}

Submit your manuscripts at

http://www.hindawi.com
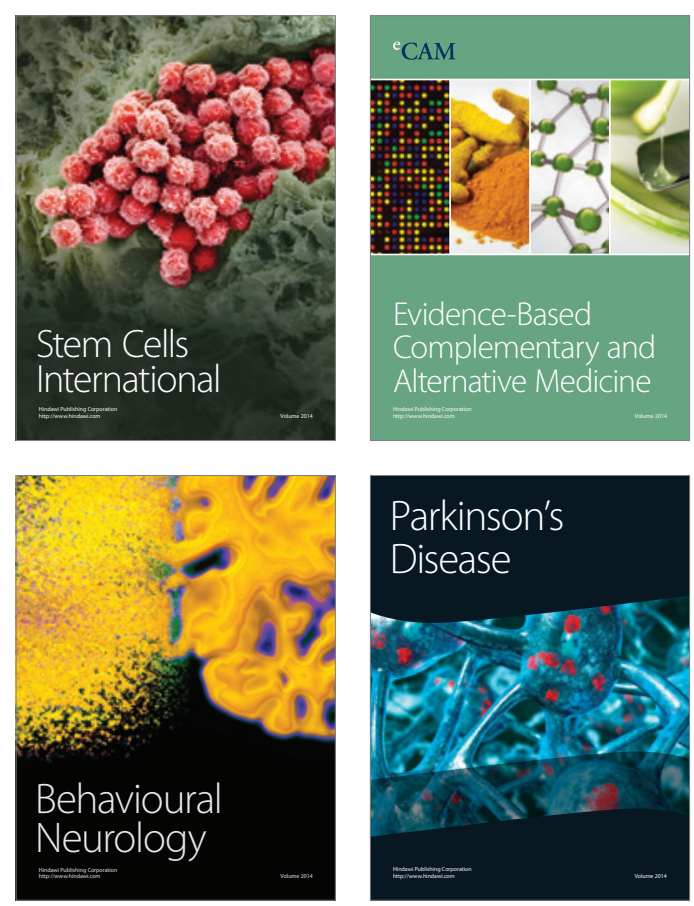

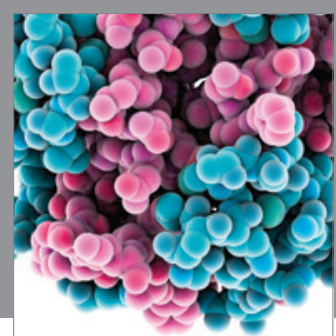

Journal of
Diabetes Research

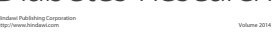

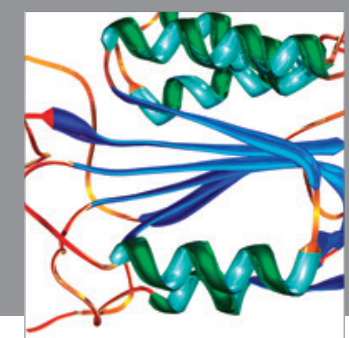

Disease Markers
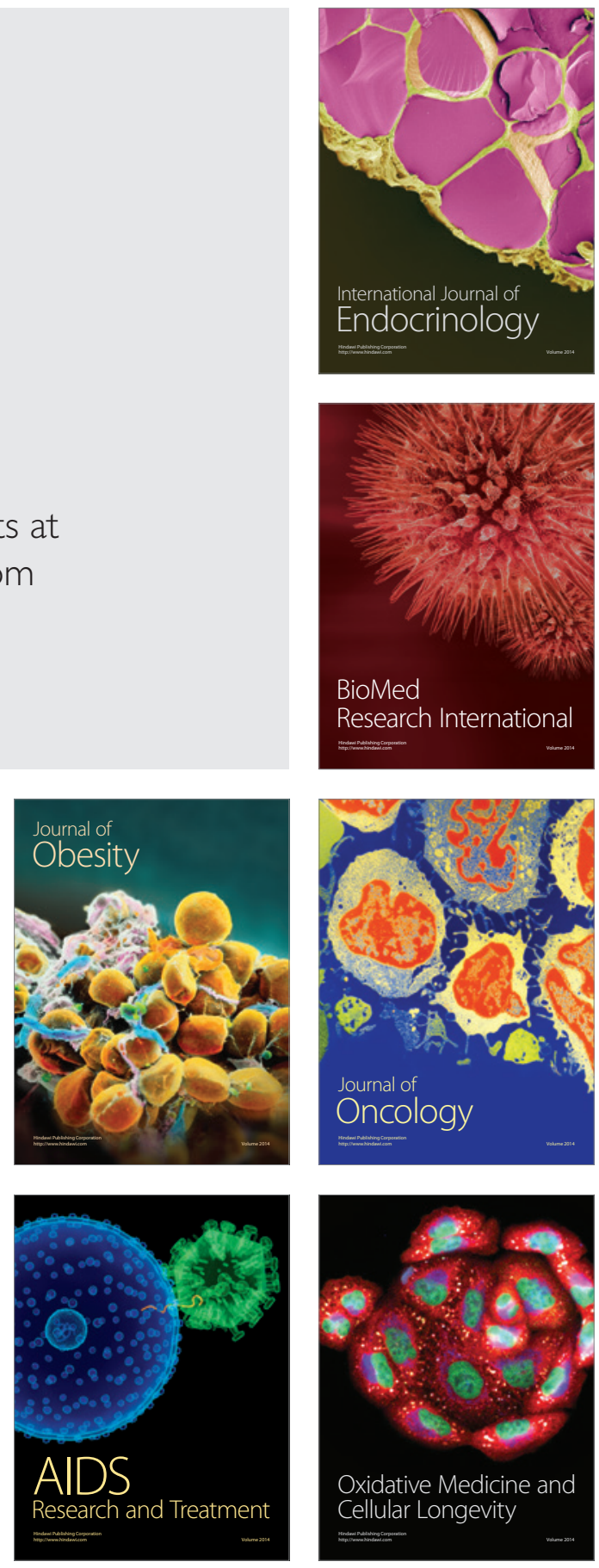